\title{
When are nonwords easy to see?
}

\author{
GROVER C. GILMORE and HOWARD E. EGETH \\ Johns Hopkins University, Baltimore, Maryland 21218
}

\begin{abstract}
The influences of presentation mode (mixed vs. blocked trials) and target variability on the detection of targets in words and in random letter strings were examined. The results indicated that there was a substantial word superiority effect in mixed lists of words and nonwords, but that this effect was eliminated when pure lists of words and nonwords were compared. Also, target variability affected the shape of the serial position curve. When subjects searched repeatedly for a single target, the serial position curve had only a significant linear component. However, when the identity of the target varied from trial to trial, the serial position curve had a significant quartic component (i.e., it was M-shaped). These results were interpreted in terms of strategies and feature learning.
\end{abstract}

A topic of considerable interest in contemporary cognitive psychology concerns the often reported perceptual superiority of familiar stimuli over unfamiliar stimuli and, more specifically, of familiar words over unfamiliar words or nonword letter strings. The word superiority effect (WSE) is an elusive phenomenon; sometimes it occurs, sometimes it does not. This is hardly surprising considering the enormous diversity among studies of the WSE.

The purpose of the present study was to select a paradigm that has been used frequently in the study of the WSE, and to systematically examine two of the factors that have differed from experiment to experiment in the past. It was our hope that we might thus resolve some discrepancies in results among existing studies and, more importantly, by ascertaining the magnitude and nature of the WSE under a variety of conditions, contribute to our understanding of it.

The paradigm of interest is the detection task in which a letter string is presented and the subject indicates whether or not it contains a predesignated target letter. Using such a paradigm, Krueger (1970) demonstrated that detection latency was shorter when the letter strings formed words than when they did not. Gibson, Tenney, Barron, and Zaslow (1972) used a variant of this paradigm in which subjects searched through a long list of letter strings searching for a specified target letter. In that study, orthographically well-structured strings were not searched more quickly than poorly structured strings. The data from forcedchoice variants of the detection task also exhibit diversity. For example, Johnston and McClelland (1973) and Reicher (1969) have demonstrated the WSE, whereas Bjork and Estes (1973) and Massaro (1973) failed to find it. This diversity of results, even within specific

This research was supported by a contract between Johns Hopkins University and the Engineering Psychology Program Office of the Office of Naval Research. Requests for reprints should be sent to the second author at the Department of Psychology, Johns Hopkins University, Baltimore, Maryland 21218. Grover C. Gilmore is now at the Department of Psychology, Case Western Reserve University. task variants, suggests that methodological factors controlled within individual studies may be varying across studies.

One potentially important difference among these studies is that in some the target (or, in a forced-choice design, the set of target alternatives) is varied randomly from trial to trial, while in other studies it is constant over a long block of trials. Estes (1975) and Gibson et al. (1972) have suggested that use of a constant target may permit subjects to process stimuli at the level of distinctive features rather than whole letters. Such a shallow processing level may not, in turn, provide any opportunity for linguistic context to operate. In line with this speculation, the studies by Johnston and McClelland (1973), Krueger (1970), and Reicher (1969) that showed the WSE used a new target or set of target alternatives on each trial, whereas the Bjork and Estes (1973), Gibson et al. (1972), and Massaro (1973) studies which failed to demonstrate the WSE all used a constant target set.

The nature of the target set cannot be the only factor that determines the outcome of detection experiments, however. For example, James and Smith (1970) used a varied target set, yet found no familiarity effect. Gibson et al. (1972) pointed out that another pertinent factor may be whether the design permits subjects to be set for processing a single kind of material (words or nonwords) or both kinds in random order. If a subject can expect a particular kind of stimulus on each trial, then he can adopt a processing strategy which is optimal for that item. This may not be achieved, however, when the stimulus type varies from trial to trial. It is interesting to note that both the Gibson et al.(1972) and the James and Smith (1970) studies used different subjects for the familiar and unfamiliar items, whereas most experiments that have obtained the WSE showed each subject both types of material in mixed lists.

In the present experiment, mode of presentation (mixed vs. pure lists of words and nonwords) and target variability were manipulated factorially to assess their effects independently and in combination. 


\section{EXPERIMENT I}

\section{Method}

Subjects. Sixteen students at the Johns Hopkins University each participated in two experimental sessions lasting about $60 \mathrm{~min}$ each. All had normal or corrected-to-normal vision.

Apparatus. On each trial a horizontal string of five letters was presented on a fast-decay CRT display controlled by a PDP-11/20 computer. The letters were composed by activating the appropriate dots in a 7 by 5 dot matrix that was $3.9 \mathrm{~mm}$ high and $2.6 \mathrm{~mm}$ wide. At the viewing distance of $64 \mathrm{~cm}$, a character subtended a maximum visual angle of $21 \mathrm{~min}$ in height and $14 \mathrm{~min}$ in width, and the interletter space was $30 \mathrm{~min}$.

Design. Two sets of target letters were used. During one session a constant set was used, in which the target was always the letter A. During the other session a varied set was used, in which the target changed from trial to trial but was always selected from the set consisting of $A, G, L, O$, and $R$. Each target within this condition appeared an equal number of times in a random order, and all targets appeared equally of ten in each of the five serial positions. In each condition, on half of the trials one and only one target was present; on the other half of the trials no target was present.

Two classes of stimulus items were used, words and nonwords. Two hundred words were chosen from the ThorndikeLorge (1944) list of words that occur at least one per million in printed English (e.g., FLOAT, GLADE, REPLY). The 200 nonwords were zero-order approximations to English (e.g., ARHND, DOSGP, LFNMA). The constant and varied target conditions were run on different days and were tested with separate sets of words and nonwords. Half of the original pool of 200 words was selected, along with half of the original pool of 200 nonwords, for use in the constant condition, while the remaining stimuli were used in the varied condition.

During both sessions (i.e., within both the constant and varied conditions), the words and nonwords were presented in each of two fashions, i.e., mixed and blocked. The blocked conditions consisted of two pure lists, one containing 100 words, the other containing 100 nonwords. Half of the subjects were presented nonwords before the words, while the other subjects were presented with the stimuli in the reverse order. The mixed condition consisted of a single 100-item list made up of 50 of the words and 50 of the nonwords from the blocked condition presented in a random order. Half of the subjects received the mixed condition before the two blocked conditions; the other half of the subjects received the mixed condition after the two blocked conditions. Analyses were based only on the responses given to that half of the total pool of stimuli that was used in both the mixed and blocked conditions.

Procedure. Each experimental session lasted about an hour and consisted of 300 data collection trials, presented as six sets of 50 trials each, with 2.5 -min breaks between sets. The two sets for each of the three conditions (blocked words, blocked nonwords, mixed) were always given one immediately after the other. Before data collection began, a subject was given 10 practice trials to acquaint him with the target set for that session, either $A$ or $A, G, L, O, R$. Subjects were informed of the nature of the list (words, nonwords, or both) at the beginning of each new condition.

A trial began with a 1-sec exposure of a target letter. Subjects were requested to fixate this character and to indicate if it occurred in the subsequent letter string. The target letter was followed by a 1 -sec blank field. The display then appeared for $100 \mathrm{msec}$, situated so that the middle letter of the five-letter string fell directly over the fixation area. If the subject detected the target in the display, he was to press a microswitch held in his preferred hand. No response was made when the target was not detected. Latencies from display onset to closing of the response switch were recorded to the nearest millisecond. A new trial was initiated $2 \mathrm{sec}$ after the onset of the preceding stimulus display.

\section{Results}

The overall error rate for both misses and false positives was only $3 \%$, hence further analysis was restricted to a consideration of reaction time differences.

A four-way ANOVA on the mean reaction time of correct responses was carried out with Mode of presentation (blocked vs. mixed), Target set (constant vs. varied), Display type (word vs. nonword), and Serial Position of target element as the variables. All main effects except for Mode of presentation were significant: Target set $[F(1,15)=5.13, p<.05, M S=17,842]$, Display type $[F(1,15)=21.04, p<.001, M S=6,795]$, and Serial Position $[F(4,60)=8.72, p<.001, M S=4,699]$. The mean reaction times for the Target set and Display type conditions are given in Table 1.

Although the main effect of Mode of presentation was not significant, this factor entered into a significant interaction, Mode of presentation by Display type $[F(1,15)=10.21, p<.01, M S=3,081]$. The sense of this interaction may be discerned in Table 2, which shows mean reaction times (RTs) for correct responses collapsed across serial position and target set. To aid in the interpretation of the basic data, a familiarity effect has been calculated for each combination of Mode of presentation and Target set by subtracting the mean RT for word displays from the corresponding mean RT for nonword displays. The most important finding that emerges from Table 2 is that the magnitude of the WSE is affected by Mode of presentation. The familiarity effect in the mixed condition was significantly greater than zero $[t(1,15)=5.02, p<.05]$. However, the corresponding familiarity effect in the blocked condition did not differ significantly from zero.

Finally, the interaction between Target set and Serial Position was significant. This effect is plotted in Figure la averaged over the other experimental factors. A trend

Table 1

Mean Reaction Times (Milliseconds) for Words and Nonwords in Constant and Varied Target Conditions

\begin{tabular}{lcc}
\hline Target Set & Word & Nonword \\
\hline Constant & 474 & 502 \\
& $(10)$ & $(12)$ \\
Varied & 496 & 528 \\
& $(12)$ & $(16)$ \\
\hline
\end{tabular}

Note-Numbers in paren theses are estimates of standard error of the mean.

Table 2

Mean Reaction Time (Milliseconds) for Blocked and Mixed Presentation of Words and Nonwords

\begin{tabular}{lccc}
$\begin{array}{c}\text { Mode of } \\
\text { Presentation }\end{array}$ & Word & Nonword & $\begin{array}{c}\text { Familiarity } \\
\text { Effect }\end{array}$ \\
\hline Blocked & 487 & 503 & 16 \\
Mixed & $(10)$ & $(11)$ & \\
& 483 & 527 & 44 \\
\hline
\end{tabular}

Note-Numbers in parentheses are estimates of standard error of the mean. 
analysis indicated that for the constant target condition only the linear component was significant, while for the varied condition the linear, quadratic, and quartic (M-shaped) components were all significant. Much the same pattern of results emerges in Figure $1 b$, where means are plotted for just those trials on which the target was a letter A. Specifically, a trend analysis revealed significant linear and quartic components for the varied condition. We shall consider the implications of the serial position curves in the General Discussion section.

\section{EXPERIMENT II}

Since the magnitude of the familiarity effect is dependent on whether stimulus lists are blocked or mixed with respect to familiarity, it is natural to think that expectancy may be a crucial factor. Specifically, it may be that different strategies are optimal for detecting target letters in words and in nonwords. With a blocked list, subjects can adopt the set appropriate to each type of stimulus and, in consequence, familiarity effects are reduced, possibly even eliminated. With mixed lists, subjects may consistently adopt the strategy appropriate to words, since these are the stimuli they are most accustomed to dealing with. If this strategy were incompatible with nonword processing, then a familiarity effect would result.

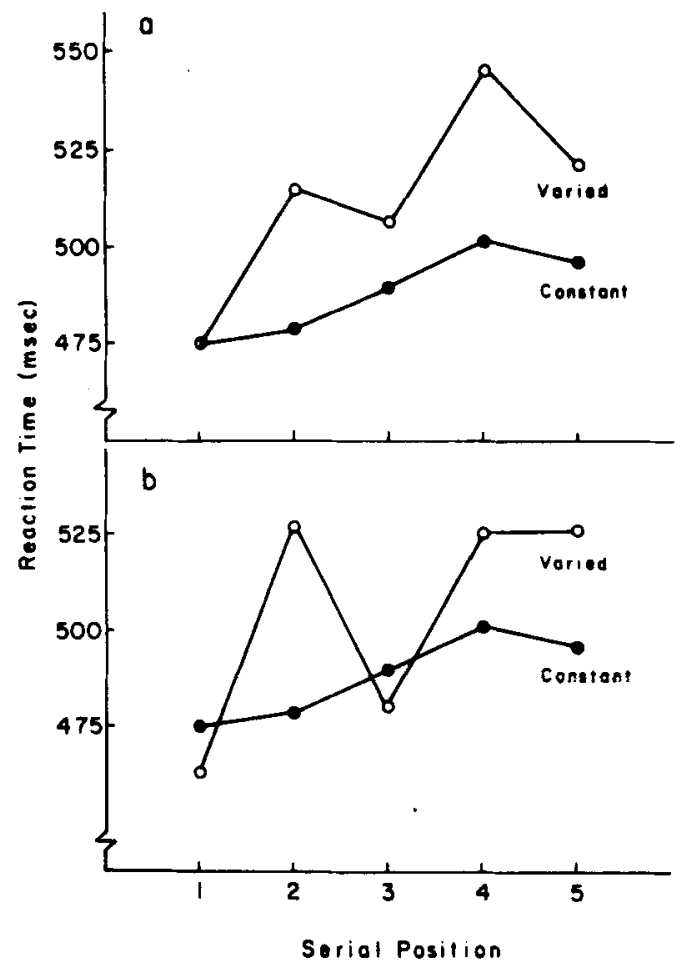

Figure 1. Mean reaction time for each serial position in the varied and constant target conditions. (a) Overall data. (b) Mean reaction time in the varied condition for those trials on which the target was the letter A. The function for the constant condition is the same in $a$ and $b$.
Table 3

Mean Reaction Time (Milliseconds) for Test Stimuli (Trials 50 and 51) in Experiment II

\begin{tabular}{lcc}
\hline \multirow{2}{*}{$\begin{array}{c}\text { Type of Item } \\
\text { Presented }\end{array}$} & \multicolumn{2}{c}{ Type of Item Expected } \\
\cline { 2 - 3 } Word & Word & Nonword \\
& 518 & 499 \\
Nonword & $(26)$ & $(20)$ \\
& 614 & 504 \\
& $(32)$ & $(16)$ \\
\hline
\end{tabular}

Note-Numbers in parentheses are estimates of standard error of the mean.

\section{Method}

To test the expectancy hypothesis more directly, we compared performance when a given type of stimulus was expected with when it was unexpected. Our method was similar to that of Aderman and Smith (1971). Sixteen naive subjects were presented the blocked stimuli described in Experiment $I$ in a single session. The major change was that after every 50 trials a specially designed test trial was given. The 50th trial was, of course, a stimulus of the same category as the preceding 49 trials of the block: Thus, performance on such trials provides a baseline for assessing performance when a stimulus type was expected. The stimulus used on the 51st trial was always of the opposite type from the stimulus used on the 50th trial, and thus provides an estimate of performance on unexpected stimuli. The serial position of the target was the same on the 50th and 51st trials, and the target letter on both of those trials in all conditions was $\mathrm{A}$. Of course, the subjects were given no advance information about the construction of the stimulus sequence.

Each subject received eight blocks of 51 trials each. Half of the subjects served in the constant target condition for the first four blocks and the varied target condition for the last four blocks, while the other subjects received the conditions in the opposite order. Within the four blocks of trials in each target condition, the first and second were either both "expect word" blocks or both "expect nonword" blocks, while the third and fourth blocks were devoted to the opposite stimulus type. The sequencing of word or nonword blocks first was balanced over subjects.

\section{Results}

Table 3 shows the mean RT for expected and unexpected words and nonwords. The data tend in part to corroborate the findings of Aderman and Smith (1971), although it should be kept in mind that we compared words and zero-order approximations to English, while they compared orthographically regular and orthographically irregular nonwords. Thus, when a nonword appeared unexpectedly after a series of words, RT on the 51 st (surprise) trial was longer than on the 50th trial for both constant (sign test, $\mathrm{z}=3.33, \mathrm{p}<.01$ ) and varied $(z=2.65, \mathrm{p}<.01)$ conditions. However, when a word appeared unexpectedly at the end of a series of nonwords, there was no significant trend toward longer or shorter RTs on Trial 51 than on Trial 50.

There are, however, some marked discrepancies between the results of our research and the results of the Aderman and Smith (1971) experiment. For one, we differ on the magnitude of the WSE when stimuli were 
Table 4

Schematic Description of Outcomes of Two Experiments on Expectancy

\begin{tabular}{|c|c|c|c|c|c|}
\hline \multicolumn{3}{|c|}{ Aderman and Smith (1971) } & \multicolumn{3}{|c|}{$\begin{array}{c}\text { Gilmore and Egeth } \\
\text { Experiment } 2\end{array}$} \\
\hline \multirow[b]{2}{*}{ Received } & \multicolumn{2}{|c|}{ Expected } & \multirow[b]{2}{*}{ Received } & \multicolumn{2}{|c|}{ Expected } \\
\hline & Word & Nonword & & Word & Nonword \\
\hline $\begin{array}{l}\text { Word } \\
\text { Nonword }\end{array}$ & $\begin{array}{l}\text { good } \\
\text { poor }\end{array}$ & $\begin{array}{l}\text { poor } \\
\text { poor }\end{array}$ & $\begin{array}{l}\text { Word } \\
\text { Nonword }\end{array}$ & $\begin{array}{l}\text { good } \\
\text { poor }\end{array}$ & $\begin{array}{l}\text { good } \\
\text { good }\end{array}$ \\
\hline
\end{tabular}

Note-Good performance is characterized in these studies by a lower mean reaction time, or a higher level of accuracy, in one condition relative to the other conditions of the same experiment.

blocked. On the first 15 trials in their experiment, subjects saw either all spelling patterns or all strings of unrelated letters, depending on the condition in which they were serving. Thus, familiarity was a blocked variable. Nevertheless, on those trials, accuracy was higher for the spelling patterns than the unrelated letters. This, of course, differs from the results of our first experiment. In addition, there is evidence in Experiment II that is also inconsistent with Aderman and Smith's (1971) data. If we consider mean RT for the 50 trials of each block prior to the surprise trial, then words $(529 \mathrm{msec})$ were not processed more quickly than nonwords (523 msec).

Another major discrepancy may be best appreciated if we compare the results of our Experiment II and Aderman and Smith's (1971) experiment in the schematic form of Table 4. In the Aderman and Smith study, performance is good only when words are both expected and presented. By contrast, in our study, performance is poor only when a subject expects a word but receives a nonword. We shall return to these points in the General Discussion section.

\section{GENERAL DISCUSSION}

The purpose of this paper was to explore the effects of two factors that have been allowed to vary between experiments in research on the word superiority effect using the detection paradigm. The factors were whether the stimuli are presented blocked or mixed with respect to familiarity and whether the target set is constant over trials or varied from trial to trial. Both factors proved to have interesting and important (but different) effects that cast light on the nature of visual information processing.

\section{Target-Set Variability}

Although this factor had a significant effect on overall RT, it proved to have no significant effect on the magnitude of the WSE. We were thus tempted to conclude that target-set variability is not an important factor in studies of the WSE. However, standing in the way of this easy interpretation is the finding of a recent study by Juola, Choe, and Leavitt (Note 1). They meas- ured accuracy of letter identification in a two-alternative forced-choice task. In one experiment, new target alternatives were used on each trial, while in another experiment, the alternatives were constant within blocks of 10 trials. The WSE obtained in the former condition but not in the latter. Unfortunately, there are so many procedural differences between our experiment and theirs that we cannot yet begin to reconcile the difference in results.

Quite apart from the (lack of) effect of target-set variability on the magnitude of the WSE, one of the other effects of target-set variability found in this study appears to have interesting implications for detection research in general. We are not referring here to the significant main effect on mean RT of target variability. Since the constant and varied conditions resulted in the same mean RT for the first serial position, it appears most reasonable to conclude that the main effect is really secondary to, and a consequence of, the interaction of Target Variability by Serial Position. It is this unexpected interaction that we find most provocative. However, since it was unanticipated, we can offer only some post hoc speculation as to its meaning.

Let us assume that all detection responses may be categorized as either primary or secondary responses (Estes, 1972). Primary responses occur whenever a criterial number of target features is detected, in any one of the information processing channels, immediately following the parallel representation of the display. If a sufficient number of target features is not detected at this time, then a more detailed serial scan of the display is initiated. Responses generated as a result of this process are termed secondary responses and, by definition, must always take longer than a primary response. Within this response framework, an adequate explanation of the serial position curves may be formed.

The elements of the linear displays in this study were spaced closely enough that lateral inhibitory effects among adjacent letters would be expected (Eriksen \& Hoffman, 1972). However, since the end elements of the display were flanked on only one side and the middle letter fell directly over the fixation point, it is reasonable to assume that the inhibitory effects on these positions are less than those on Positions 2 and 4 (Wolford \& Hollingsworth, 1974). Of course, another reason for relatively good performance at Position 3 is that acuity is highest at the fixation point. A direct result of these display characteristics is that fewer letter features should be represented on the average in Positions 2 and 4 than in the remaining positions if we assume that the inhibitory effect on Positions 2 and 4 is greater than the effect of lower acuity on the peripheral positions, 1 and 5. A processing consequence will be that fewer primary responses are signaled from these two relatively degraded positions. Thus the $M$ shaped serial position curve (Figure 1) evident in the varied target condition may be directly related to the 
number of primary responses attributed to each position on the basis of lateral inhibitory influence.

Given this analysis, how may we account for the linear functions obtained in the constant target condition? We assume that in the constant condition, unlike the varied condition, subjects may be able to respond on the basis of any one of several available features. In other words, we assume that the criterial number of features required for a primary response is smaller in the constant than in the varied condition. If the number of criterial features is less than or equal to the number of features remaining in the most degraded serial position, then the number of primary detections will be roughly evenly distributed across serial positions, thus eliminating the quartic component of the serial position function. The remaining linear component is, of course, attributable to the left-toright serial scan required when primary detection fails. But why should primary detection ever fail in these circumstances? This is not entirely clear. It may be that on some trials the subject is simply not set to use the primary detection strategy. Or it may be that the primary and secondary processes are going on in parallel, in a race that is not always won by the primary process. ${ }^{1}$

It is worth noting that the preceding analysis hinges only upon a quantitative distinction between more or fewer distinctive features. We have not demonstrated here a qualitative difference between processing distinctive features and processing letters as whole units, although such a demonstration may be possible.

\section{Blocking vs. Mixing}

The reduction, or possibly even the elimination, of the WSE as a result of presentation of materials in a blocked format has a close counterpart in some research on a rather different kind of familiarity effect. Egeth and Blecker (1971) reported that when subjects made "same"-"different" judgments about letter pairs, response latency for "same" judgments was slowed when the letters were shown upside down. In that study, upright and inverted pairs were randomly mixed. Subsequently, Egeth \& Gilmore (Note 2) reported that when the stimulus pairs were blocked with respect to orientation, the differential in RT disappeared. It was suggested that the distinctive features of letters tend to appear in different spatial positions for upright and inverted letters, toward the right and left, respectively (cf. Koler, 1969). Thus, different processing strategies may be used by subjects with the two kinds of stimuli, e.g., looking toward the left or right. In a mixed list, subjects would probably adopt the strategy appropriate to the more usual upright letters, and a "familiarity" effect would result.

In the present experiment the differential strategies are by no means obvious, but it is nevertheless tempting to speculate what they may be. When a word is expected, subjects may attempt to (or, indeed, may involuntarily have to) use their knowledge of English redundancy and orthography to aid in locating and identifying the target letter. Given the preceding description of target detection, based on primary and secondary responses, it is consistent to postulate this effect as part of the secondary response stage. When a primary detection does not occur, the subject must resort to a more detailed analysis of the individual elements. He may, however, be able to use the information concerning the identity of the nontarget elements that he picks up during this process, to direct his analysis to the critical target position. When a nonword is expected, the subject does not attempt to use any available information concerning the identity of the nontarget characters to direct his search; rather, he treats the entire array as a random string of letters.

The relatively poor performance on nonwords in the mixed conditions is explained by appeal to the idea that subjects choose to first treat all stimuli in the mixed condition as if they were words. This, of course, is appropriate only half the time. The other half of the time this fails because subjects cannot use or are misled by the unreliable information on target position conveyed by the nontarget elements, and must try again with the alternative strategy. Note that this is not an optimal strategy, since the blocked data suggest that a subject would be better off treating all stimuli as nonwords. This point deserves further investigation; it suggests the possibility that processing as a word may be mandatory under some conditions.

It is instructive to compare the results of blocking that we have observed with the results obtained in a study by Manelis (1974). He used a forced-choice tachistoscopic recognition task to compare the perceptibility of words (e.g., BAND, LAND) and of pronounceable nonwords (e.g., BANT, LANT). The data revealed that the WSE was at least as large in blocked conditions as in mixed conditions. It seems that the most likely explanation of this discrepancy is that the kinds of stimuli used by Manelis (1974) did not lend themselves to different processing strategies in blocked and mixed conditions, as did our words and zero-order approximations to English. Since all of Manelis's stimuli were highly pronounceable, subjects may have tried to encode them phonologically in both mixed and blocked conditions. We further suggest that, given an initial phonological encoding, access to the further processing that results in the WSE is automatic and not controlled by expectancy.

The same kind of analysis may be applied to the discrepancy in the pattern of results of the Aderman and Smith (1971) experiment and the present Experiment II (Table 4). The issue comes down to understanding why performance is uniformly poor when their subjects expected nonwords but uniformly good when our subjects expected nonwords. Our expectancy-inducing nonwords may have been linguistically intractable, 
since they were zero-order approximations to English. According to our supposition above, this should have induced what turns out to be a highly efficient strategy of feature analysis in the secondary detection stage which should work well even if a subject received a word on a surprise trial. In the Aderman and Smith (1971) experiment, we assume performance was uniformly poor when unrelated letter strings were expected because these stimuli, while they did not follow regular English orthography, may not have been so unpronounceable as to induce this efficient strategy (some sample spelling pattern stimuli: STARM, SWILG, SCORG; some sample unrelated letter strings: RMAST, LGISW, RGOSC). In any event, these subjects had only 15 trials to perfect their strategy before the final test trial. It is possible that with many more trials they would have adopted a different and more efficient strategy. ${ }^{2}$

It is obvious from the results presented here that slight differences in experimental design, as have existed in the study of the WSE, can profoundly influence the outcome of a study. Specifically, when words and nonwords were presented in a mixed random order, a strong WSE was present. However, this effect disappeared when the same words and nonwords were presented in separate blocks of trials. The blocking of the stimuli sets the subject and allows the establishment of a processing strategy appropriate for each kind of material. A similar set effect is also apparent in the striking difference between the serial position curves of the constant and varied target conditions. When a subject is dealing with the same target on every trial, he can assume a processing strategy which takes advantage of the redundant and distinctive features of that target.

\section{REFERENCE NOTES}

1. Juola, J. F., Choe, C. S., \& Leavitt, D. D. A reanalysis of the word-superiority effect. Paper presented at the annual meeting of the Psychonomic Society, Boston, November 1974.

2. Egeth, H. E., \& Gilmore, G. C. Perceptibility of the letters in words and nonwords with complete control of redundancy. Paper presented at the meeting of the Psychonomic Society, St. Louis. November 1973.

\section{REFERENCES}

Aderman, D., \& Sмith, E. E. Expectancy as a determinant of functional units in perceptual recognition. Cognitive Psychology. 1971. 2. 117-129.

BJORK. E. L.. \& Estes. W. K. Letter identification in relation to linguistic context and masking conditions. Memory \& Cognition. 1973, 1, 217-223.

Egeth, H. E., \& Blecker, D. L. Differential effects of familiarity on judgments of sameness and difference. Perception \& Psychophysics. 1971. 9. 321-326.

Estes. W. K. Interactions of signal and background variables in visual processing. Perception \& Psychophysics. 1972. 12. 278-286.

Estes, W. K. Memory, perception, and decision in letter identification. In R. L. Solso (Ed.), Information processing and cognition. Hillsdale. N.J: Lawrence Erlbaum, 1975.

Eriksen, C. W., \& Hoffman, J. E. Temporal and spatial characteristics of selective encoding from visual displays. Perception \& Psychophysics, 1972, 12, 201-204.

Gibson, E. J., Tenney, Y. J., Barron, R. W., \& Zaslow, $M$. The effect of orthographic structure on letter search. Perception \& Psychophysics, 1972, 11, 183-186.

James. C. T.. \& Smith. D. E. Sequential dependencies in letter search. Joumal of Experimental Psychology. 1970. 85, 56-60.

Johnston. J. C., \& MCClelland, J. L. Visual factors in word perception. Perception \& Psychophysics. 1973. 14. 365.370 .

Kolers, P. A. Clues to a letter's recognition: Implications for the design of characters. Joumal of Typographic Research. 1969. 3. 145-168.

KRueger. L. E. Search time in a redundant visual display. Journal of Experimental Psychology, 1970, 83, 391-399.

Manelis. L. The effect of meaningfulness in tachistoscopic word perception. Perception \& Psychophysics. 1974. 16 182-192.

Massaro, D. W. Perception of letters, words, and nonwords. Journai of Experimental Psychology. 1973, 100. 349े-353.

Reicher. G. M. Perceptual recognition as a function of the meaningfulness of the material. Journal of Experimental Psychology, 1969. 81, 275-280.

THORNDIKE, E. L.. \& LORGE, I. The teacher's word book of 30.000 words. New York: Teachers College, Columbia University, 1944.

Wolford. G., \& Hollingsworth. S. Retinal location and string position as important variables in visual information processing. Perception \& Psychophysics, 1974, 16, 437-442.

\section{NOTES}

1. We are indebted to an anonymous reviewer both for asking why primary detection should fail and for suggesting these possible reasons.

2. It is interesting to note that if the preceding speculations are correct, then the results of our experiments might have been quite different had we used some form of nonwords other than zero-order approximations to English.

(Received for publication June 12, 1975; revision accepted January 15.1976. ) 